\title{
Beyond 'oversight': A problem-oriented approach to police reform
}

\author{
Louise E. Porter
}

ARC Centre of Excellence in Policing and Security (CEPS), Griffith University, Brisbane,

Australia

Correspondence:

ARC Centre of Excellence in Policing and Security (CEPS)

3.01, Social Sciences Building (M10)

Mt Gravatt Campus

Griffith University

Messines Ridge Road

Mt Gravatt Qld 4122

Australia

Email: 1.porter@griffith.edu.au

Tel: +61 737351035

Fax: +61 737351033 


\title{
Beyond 'oversight': A problem-oriented approach to police reform
}

\begin{abstract}
This paper looks beyond the traditional compliance-based model of police oversight to discuss the emerging contributions of external oversight agencies to proactive police reform. Drawing on the approach of Problem Oriented Policing and the SARA problem solving model, the paper provides a framework to highlight a number of activities that identify and analyse problems in the police integrity domain, and design and implement solutions that impact positively on the police and communities. The paper provides examples of agency activity for each stage of the SARA model (Scan, Analyse, Respond, Assess) and case studies to illustrate the whole model in practice.
\end{abstract}

Keywords: oversight, police integrity, problem-oriented, SARA, police reform 


\section{Beyond 'oversight': A problem-oriented approach to police reform Introduction}

While police oversight agencies continue to invest resources into reactive complaint handling or review functions, the role of these agencies is widening to reflect a more holistic approach to police reform. Oversight roles now frequently include education, training and consultancy/advisory services, as well as making recommendations regarding policy and practice issues, addressing systemic reform rather than simply providing case-by-case judgments. Similarly, within police agencies, what were once known as Internal Investigations (or Internal Affairs) departments are now being relabelled as Professional Standards departments, reflecting a similarly broad responsibility for standards of conduct across organisations. The widening of these respective roles has produced an interesting duality to the relationship between these agencies. While the reactive investigation and review functions of oversight agencies still conform to a compliance-based system, a more collaborative relationship has formed under the function of improving the police service more generally. This latter role implies a shared goal of reform that prescribes mutual prevention efforts to address emerging issues. This paper outlines the contributions that oversight agencies can, and do, bring to police reform, with a focus on proactive activities. The paper outlines how a problem-oriented approach can help to frame these efforts and promote the value of partnerships between oversight and law enforcement agencies to improve police services to the community.

\section{Traditional Purpose of Oversight Agencies}

The tradition of external police oversight emerged in the latter part of the $20^{\text {th }}$ century in response to a number of commissions of inquiry and exposés of corruption, misconduct and criminal activity by police officers (Prenzler \& Ronken, 2001; Smith, 2009). Examples 
include the Knapp Commission (1972) and Mollen Commission (1994) in the US, the Scarman Report (1981) in the UK and the Fitzgerald Inquiry (1989) and Wood Royal Commission (1997) in Australia. All called for the creation of independent agencies to increase external accountability for police. Agencies were recommended to have investigatory powers that would preclude the police from investigating their own members internally for serious misconduct. The purpose of such powers was to increase public confidence that investigations of police officers would be conducted with greater scrutiny and fairness, with suspicions that police internal investigations were biased towards subject officers, being at best too lenient and, at worst, involving intimidation of complainants and witnesses.

\section{Traditional Models of Oversight}

Internationally, oversight agencies have been created with differing models and powers, which are also evolving rather than static (although subject to legislation and resources). Typically, over time agencies have been provided with increased powers, as well as widened roles. However, at the same time, there is an increasing movement towards handing back the responsibility of complaint handling and investigation to the police themselves, particularly for less serious matters.

Prenzler \& Ronken (2001) discuss two main models of external oversight - 'civilian review' and 'civilian control' - while in the US, Walker (2001) offered four classes of oversight models. The basic distinction between the models described by these authors lies with the amount of independent power that the oversight body has to investigate the police agency. At the lowest end of the spectrum are models that reflect an oversight agency's ability only to review or audit police internal investigations. At the highest end of the spectrum, investigations of the police are conducted externally, with the oversight body 
having its own independent investigative capacity, often with significant powers and resources. Whilst this higher level of external oversight is typically proposed as best practice, it has also been acknowledged that such a degree of external involvement can actually reduce internal organisational responsibility for integrity (Porter \& Prenzler, 2012a; Prenzler \& Ronken, 2001).

According to Livingston (2004), the impact of citizen oversight is deterrence-based. She states that citizen involvement in the complaint process should increase the fairness and thoroughness of investigations. Deterrence occurs where these improved investigations lead to an increased likelihood of consequences for misconduct through the enforcement of rules and disciplinary action. As Livingston explains,

With better investigations, the theory goes, more complaints will be sustained, resulting in more discipline of officers who have committed acts of misconduct. More discipline in turn will lead to greater deterrence of police abuse.

(Livingston, 2004, p.654)

Underpinning Livingston's explanation of deterrence is a process of transactional influence on behaviour, whereby individuals are influenced externally by reward and punishment. This is in contrast to transformational influence that attempts to change behaviour internally, through instilling certain values. The latter corresponds to principles of co-operation (as opposed to compliance), where goals are shared and members behave in ways that are consistent with their own moral decision-making; this means that influence operates in the absence of surveillance (Kelman, 1958). In theory, this form of organisational influence can, therefore, be more successful and less costly than influence that relies on instrumental inducements (reward and punishment) for employee behaviour (Tyler \& Blader, 2005). 
Whilst oversight efforts may have begun with deterrence, there are a number of valuesbased integrity strategies that have emerged to prevent problems of misconduct and corruption. For example, codes of ethics, ethics training, support for employees who report misconduct, and integrity-based promotions criteria are increasingly in use within police agencies. External oversight agencies are also broadening their repertoire of strategies to be proactive. Moving beyond deterrence theory to transformation-based influence on police reform may increase the impact of oversight agencies on the policing environment through modifying values and increasing the investment of police in shared goals. However, the effectiveness of such efforts would likely hinge on the extent of inter-agency collaboration, trust and ownership in tackling problems.

\section{Problem-oriented Approach}

Problem-oriented policing was first conceptualised by Herman Goldstein in 1979 (Goldstein, 2003) and has become increasingly popular with both academics and law enforcement agencies, predominantly in tackling particular forms of crime. The approach recognises the range of problems concerning policing and that each may require a different solution. The approach emphasises the importance of analysis to identify the problem and tailor solutions that can be implemented not just by police, but in partnership with external stakeholder agencies. Thus, problems are identified as being salient for both police and communities, and the approach is collaborative. The approach also emphasises creative solutions to identified problems and the evaluation of their impact:

The concept carries a commitment to implementing the new strategy, rigorously evaluating its effectiveness, and subsequently reporting the results in ways that will benefit other police agencies and that will contribute to building a body of 
knowledge that supports good practice and ultimately, thereby, will also contribute toward the further professionalization of the police.

(Goldstein, 2003, p.14)

Some authors have highlighted the potential of a 'problem-oriented' approach to law enforcement oversight through utilisation of complaints data to highlight key issues (Walker, 2001). Livingston (2004) asserts that, just as police have begun to embrace a problemoriented approach with the recognition that the wide range of problems facing police requires methods beyond enforcement of the law, so too should oversight agencies expand their role beyond rule enforcement. She discusses four principles of a problem-oriented approach to citizen review: "triage" of complaints, complaints "information gathering and analysis", the “involvement of [subject-officers'] line supervision" in the complaints process, and "monitoring the complaint review process". However, Livingston recognises that such a process requires collaboration between oversight agencies and police and that this raises questions as to the independence of the oversight agency:

Much of what is proposed here requires that participants in the citizen review process work more closely with police to see that the information contained in complaints is effectively used to better the police organization and enhance police services.... Can the citizens in citizen review processes maintain their independence (and be perceived as independent) in light of this closer collaboration?

(Livingston, 2004, p. 669). 
Indeed, Grabosky and Braithwaite (1986) and Prenzler (2000) discuss agency 'capture' as a risk of close working relationships between staff of agencies that should be independent. However, Livingston (2004) argues that the role of civilian oversight should be broadened now beyond the 'first generation' of merely providing independent scrutiny, to a second generation role of ensuring that the wider problems raised in complaints are adequately addressed by police organisations.

\section{SARA model}

One method, and perhaps the best known, for undertaking problem-solving in policing is the SARA problem-solving model (Eck and Spelman, 1987). SARA represents the four stages of Scanning (identifying a problem), Analysing (collecting data to inform the scope or cause of the problem), Responding (developing and implementing solutions to the problem) and Assessing (evaluating the effectiveness of the response). The process can be cyclical, in that the results of the evaluation can be fed back into understanding the problem and monitoring the need for further intervention. However, the process is not necessarily linear (involving all stages, or in this order) and the SARA model is only one model of the problem solving process; other variations have also been presented (for example see Ekblom, 2005, and Read \& Tilley, 2000). However, as a conceptualisation of the basic stages of understanding and responding to a problem, and expanding on the idea of problem-oriented oversight, SARA is presented in the current paper as a guiding framework to understand the contributions (both real and potential) of oversight agencies to police problem-solving, or police reform.

[Insert figure 1 here]

\section{Problem-oriented Approach to Police Reform}


Figure 1 depicts the stages of the SARA model and how they relate to the general process of identifying a problem, producing and implementing solutions, and evaluating the impact of those solutions. This section discusses each stage of the SARA model with reference to the potential contributions of oversight agencies and examples of current practices that illustrate these contributions. This is then followed by two case study examples that demonstrate the whole SARA process.

\section{Stages of the SARA model}

Scan

Many authors (including Livingston, 2004 as previously mentioned) have highlighted that oversight agencies at all levels, accumulate information about the policing environment that can be used to build a picture of potential areas of concern. At the lowest, or most basic, level of oversight, agencies may receive appeals from unsatisfied complainants, or audit police systems for complaints handling or other practices. For example, in the UK, the office of the Police Complaints Commissioner for Scotland (PCCS) has only a complaint review function but initiated an audit of the complaints handling process of one jurisdiction after a complaint handling review raised concerns (PCCS, 2008). The PCCS has also undertaken, on its own initiative, an audit of the accessibility of police complaints procedures (PCCS, 2009).

At a more detailed level, the Corruption and Crime Commission, oversight agency to the Western Australia Police, conducts in-depth 'systems-based evaluations' (Porter \& Prenzler, 2012a) to audit police practices in a variety of areas (geographically-based and subject/procedures-based). This audit process goes beyond dip-sampling cases for purposes of rule enforcement and involves site visits and discussions with personnel to provide a more educative presence. 
At a higher level of oversight, agencies may independently receive and investigate complaints or reports of potential misconduct. Patterns may be identified between a number of cases handled by the agency that suggest systemic issues, or individual matters may be viewed as particularly serious or of significant public interest and deemed as warranting further inspection. However, while issues may be recognised by staff on such a case-by-case basis, the observance of patterns of incidents, or existence of systemic problems is more efficient with the keeping of databases that allow statistical examination of cases by a range of features, such as the subject of the complaint, location, the issues involved, and so on. To this end, some oversight agencies are tasked with compiling local or national statistics on complaints. For example, the PCCS, mentioned above, collects statistical information from Scottish police districts and compiles this into a report on complaint numbers, while the Independent Police Complaints Commission (IPCC) for England and Wales collects raw complaints data from the 43 police forces and produces its own statistical trend analysis for public reporting (Porter \& Prenzler, 2012b).

Other oversight agencies are the sole keepers of complaints databases. In Northern Ireland, the Police Ombudsman (PONI) receives all complaints against the Police Service of Northern Ireland (PSNI) and produces large amounts of statistical outputs, both publicly on its website and in reports to PSNI units. This descriptive data allows police managers to interpret the problem areas, or indeed people, under their supervision (Porter \& Prenzler, 2012b). In Australia, the States of New South Wales and Queensland have systems that allow both the police and oversight agencies real-time access to one centralised complaints database, and can, therefore, utilise this information for 'intelligence-gathering' purposes (periodic scans or focussed on particular areas of concern) (Porter \& Prenzler 2012a). In Canada, the Commission for Public Complaints Against the Royal Canadian Mounted Police 
(CPC) operates an early invention system - the Multiple Complaint Member Project whereby it identifies

RCMP members who are subject to three or more public complaints, where the allegations are serious in nature (e.g. improper use of force, improper use of firearms) within a 12-month period. Once a member is identified under the current criteria, the CPC shares this information with the RCMP, which is then able to communicate the information to the relevant division and/or detachment.

(CPC, 2011, p. 12).

Some oversight agencies also conduct wider environmental scans of issues to proactively seek out emerging trends in policing and to inform possible areas of focus for their own jurisdictions. These can be produced as public literature reviews or agency briefing reports. For example, The Police Integrity Commission (PIC) in Australia published a review of Early Intervention Systems (Bertoia, 2008), and the CPC in Canada produced a review of literature on in-custody deaths (CPC, 2009).

The information accessible to oversight agencies can, therefore, be extensive and an important source for recognising trends or systemic issues, or other matters of significance that may warrant further scrutiny. Thus, oversight agencies are often in a prime position for proactive problem identification.

\section{Analyse}

The section above included the scrutiny of data for identifying problems at the descriptive level and intelligence gathering. Many oversight agencies are also involved in conducting more sophisticated, targeted forms of analysis around particular identified problems. This includes analysis of data held on agency databases (described above), as well as conducting additional forms of data gathering and analysis through specific research initiatives. 
There are numerous examples of oversight agencies undertaking targeted data analysis of specific problem areas. For example, in Australia, the Office of Police Integrity (OPI) in the State of Victoria (oversight agency to the Victoria Police), conducted a Review of the Use of Force by and Against Victoria Police (2009) incorporating analysis of data from Victoria Police's use of force reporting system. The review highlighted necessary improvements in policy, training, monitoring, and reporting practices and urged Victoria Police to utilise that data more strategically and "demonstrate a commitment to strategically managing the risk associated with inappropriate use of force" (OPI, 2009, p. 58).

In the UK, the IPCC for England and Wales undertook analysis of all cases in their jurisdiction of deaths in or following police custody over an eleven year period from 1998/99 to $2008 / 09$ and reported on trends in the data that highlighted failings of police duty of care, particularly in the assessment and monitoring of persons in custody. This led to specific recommendations for both police and health care services to improve practices. Similarly, the IPCC has collated and conducted analysis of over 100 investigation reports of road traffic incidents involving the police that have resulted in a fatality or serious injury (Docking, Bucke, Grace \& Dady, 2007). Recommendations of that report have resulted in revised pursuit guidelines.

Oversight agencies are increasingly engaging in primary research; that is, collecting new data for analysis. In Australia, some States have oversight agencies that are heavily involved in research, with dedicated research teams or units. In New South Wales, for example, the Police Integrity Commission has conducted and published reports on a range of research projects. Recent landmark projects explored and identified potential misconduct risks of individuals (Project Odin: PIC, 2009) and work places (Project Manta: Gorta, 2011) in order to highlight a framework for proactive prevention efforts. In Queensland, the Crime and Misconduct Commission (and its predecessor the Criminal Justice Commission) has 
collected survey data on the Queensland Police Service (QPS) recruits and First Year Constables yearly since 1995 to monitor ethical attitudes towards a range of scenarios. A $2010 \mathrm{CMC}$ report on this data noted decreased ratings of seriousness of, and willingness to report, certain unethical behaviours in recent years as a potential area of concern for the QPS (CMC 2010).

In the UK, the IPCC conducted a project to take stock of their early years of operation around complaints handling. The work incorporated stakeholder discussions and the collection of survey data, which identified dissatisfaction with the complaints handling system as well as under-access of the system by certain groups. The outcome of the work was a new Statutory Guidance for police complaint handling that the IPCC launched in 2010 (IPCC, 2010). The IPCC noted (see Porter and Prenzler, 2012b) that part of the success of the implementation of the Statutory Guidance was the high level of stakeholder input in its inception, with a number of police agencies/personnel engaging in discussions with the IPCC.

Indeed, in some cases, research and analysis is conducted through collaboration between police agencies and their oversight bodies. This could involve the police agency approaching the oversight agency to utilise their research resources, an oversight agency involving the police in the conduct of a project, or a fully collaborative research endeavour. In-depth analysis of identified problems enables the specific nature of problems to be explored and for possible causes to be highlighted. This allows for a more informed response.

\section{Respond}

As outlined previously, police oversight agencies were traditionally established to respond to problems of police misconduct, but typically did so on an individual case-by-case basis and in response to a particular complaint of wrongdoing. Responses in these circumstances have included investigations, reviews, targeted audits, and even adopting sophisticated covert 
methods such as targeted integrity testing. However, beyond a reactive ad hoc response, there are a number of more positive, proactive strategies that oversight agencies are beginning to adopt to address problems uncovered by the means outlined above.

Oversight agencies frequently have the capability of making recommendations to improve police practices at the wider level, based upon their work in assessing and analysing problems. Recommendations in these cases are typically directed towards improvements and can concern systems, policies, procedures, training, or any other area of policing. For example, the work highlighted above of the IPCC in relation to traffic incidents recommended changes to UK police pursuit policies, while the work of the OPI made recommendations to Victoria Police regarding their use of force.

However, while oversight agencies have the power to make such recommendations, they rarely have any power over police to accept and implement them. Police can be held to account publicly to explain their position, but ultimately the way the police agency 'does business' is up to the head of that agency. Thus, while public shaming can be an effective 'stick' to move an agency to change, collaborative efforts in the area of recommendations and implementation are increasingly adopted. Many oversight bodies now involve their police agencies in discussions of the findings of their research activity and the development of recommendations (Porter \& Prenzler, 2012a). Indeed, such collaboration can result in recommendations having been discussed, actioned and implemented before the oversight agency's official report is released. It is widely recognised that resources and operational issues known best to police can create barriers to oversight agency-recommended practice. Oversight agencies are often held to account for the number of recommendations they make that are implemented, as an indicator of their performance in terms of providing impact. While it is recognised that oversight bodies should not be making 'easy' recommendations to increase their performance profile, there is perhaps room for flexibility in the measurement of 
implementation to focus more on the intent of the recommendation rather than the specific practical operation of that intent. Thus, often it is necessary for police agencies to propose their own ways of meeting the intent of a recommendation to ensure its feasibility. Involvement of police at this level also increases police agency engagement and ownership over solutions.

Indeed, in support of police agencies implementing their own changes, many oversight bodies are developing their role in the areas of education and advice. For example, in the UK both the IPCC and the PCCS produce publications of the lessons to be learned from particular cases that they see, in order to promote the consequences of certain wrongdoing and provide information on best practice to avoid future similar cases. Other agencies are also involved in officer training and providing toolkits for officers to use to aid decision-making. For example, in Australia the OPI has a Corruption Prevention and Education Unit ${ }^{1}$ that provides a range of educational and advisory services to the Victoria Police, including training sessions, consultancy and educational resources. OPI recently published an Ethical Health Assessment Tool (OPI, 2012), a self-assessment tool for law enforcement agencies to measure the strength of integrity systems. The CMC also provides guidance and toolkits to Queensland police officers (and other public sector agencies). For example, the CMC has produced a number of publications on managing conflicts of interest. These activities help to equip the police with the knowledge to tailor their own responses to problems. However, it is important that responses are targeted, informed and are followed up with appropriate evaluation to assess their impact.

\section{Assess}

\footnotetext{
${ }^{1}$ http://www.opi.vic.gov.au/index.php?i=58\&m=36\&t=1
} 
The final stage of the SARA model is the assessment, or evaluation, of any response recommended or implemented. Many oversight agencies perform a compliance-oriented function of monitoring, or auditing, whether recommendations have been accepted and implemented adequately by the police. The OPI in Australia, for example, maintains a database of the systemic recommendations it has made and the progress of the Victoria Police on accepting and implementing these (Porter \& Prenzler, 2012a). The CPC in Canada publishes details on its website of recommendations that remain to be implemented by the RCMP (CPC, 2010). Indeed, as mentioned previously, numbers of recommendations made and accepted are reported publicly by many oversight agencies as part of their own performance framework.

While this process is important, it does not provide evaluation of whether the response has actually met the intended outcomes or had the desired effect. Effectiveness needs to be measured for a number of reasons, including informing on whether the problem has been 'solved' or if an alternative intervention is necessary; informing the allocation of resources; understanding how similar problems in the agency might be tackled; or demonstrating how other agencies could implement similar responses. Indeed, many oversight bodies publish extensively on the results of their work, particularly reports on individual investigations or complaint reviews. However, public reports of formal evaluations are much less prevalent. In the UK, the IPCCs work on deaths in custody (IPCC, 2011) reported a marked decrease in deaths over the 11 year period of study, as well as decreases by particular causes of death, and drew inferences on a number of possible influences on this decline. The report highlighted changes in laws and guidelines, improvements in cell design, hospitalisation of arrestees, assessments and closer monitoring of detainees, provision of health services to detainees and a custody visitor scheme. However, this work did not directly assess the impact 
of the introduction of these interventions specifically. Rather, it provided a retrospective analysis of cases.

In order to fulfil the evaluation component of the process, the impact of the response must be assessed on the basis of what was intended. In other words, there needs to be clarity at the outset regarding the purpose of the response, what the indicators of success should be and how those can be measured. Indeed, sometimes monitoring and evaluation requires the collection of specific data and so it may be wise to plan for this at the point of designing the response. For example, perhaps the gathering of appropriate data, or establishing the mechanisms to do so, should be included in the initial recommended response plan.

\section{Case Study Examples of Problem-oriented Police Reform}

The section above presented ways that oversight agency activities can contribute to each of the stages of the SARA model. The following section presents two, more in-depth, case studies that illustrate the full SARA process utilised in oversight-police partnership projects, including the evaluation of impact.

Case study: Portland, USA

The full SARA process can be illustrated with the example of the Portland Force Task Force, a joint initiative between the Portland Police Bureau (PPB) and Portland's Independent Police Review (IPR) Division. In 2006, these two organisations established a Task Force, with members from both the PPB and IPR, as well as from Portland's Citizen Review Committee. The goal of the Task Force was to review the PPB use of force activity, policies and training, with comparisons to similar jurisdictions, and to highlight potential areas of improvement.

Portland Police Bureau instigated a new use of force reporting system for its officers in 2004, reporting to be one of only a few similarly-sized police departments in the US to 
publicly report on this activity (Force Task Force, 2007, p. 4). The Force Task Force analysed the use of force data held by the PPB, among other sources of information. They reported their findings publicly (Force Task Force, 2007), making 16 recommendations across the areas of data collection and analysis, policy and training, supervision and management, and intra-bureau patterns of force. The recommendations were designed to improve the Bureau's management of force and reduce the number of community complaints involving force. The majority of recommendations were specifically directed towards the Police Bureau and the Chief of Police agreed to their implementation and invited a follow-up assessment. The 2008 follow up by the reconvened Task Force assessed the implementation of the recommendations and agreed that at least the intent of all 16 had been met. The Task Force further analysed the use of force report data of the Police Bureau to evaluate the impact of the changes. The Task Force reported decreases in uses of force and citizen complaints of excessive force, as well as decreases in both officer and citizen injuries (Force Task Force, 2009).

This case illustrates the value of collaboration between the police and external agencies using an approach similar to the SARA model. The Task Force scanned the environment (similar police departments) and analysed data to highlight specific problems of citizen complaints and agency management of force. The collaborative Task Force provided a number of recommendations, with the actual implementation left to the agencies concerned (those subject to the recommendation). The changes were assessed and evaluated collaboratively by the Task Force in order to follow not only that the response was adequate but also what impact that response was having on the problems identified at the analysis stage. Thus, the response was evaluated against the intended effects. The reports provided by the Task Force were made public. They highlight that the process was challenging but comment on the 'maturity' of the Portland Police to be internally critical, and to accept both 
criticism and reform showing a commitment to improving its services to the public (Force Task Force, 2009, p. iii-v).

\section{Case study: Queensland, Australia}

In Australia, the Queensland Police Service (QPS) and their oversight body the Crime and Misconduct Commission (CMC) jointly undertook a review of the QPS Taser policy, procedures, training and monitoring. The joint review was initiated by the Minister for Police, Corrective Services and Emergency Services in the wake of a Taser-related death in Queensland during state-wide roll-out of Tasers to QPS officers. The roll-out of Tasers was put on hold while the joint review team conducted their work. The review team consisted of officers from both the CMC and QPS who had experience and background in relevant issues such as use of force, operational skills and tactics, and risk management.

The team undertook a review of the available literature on Conducted Energy Weapons (CEWs), particularly research from the US and Canada, as well as an audit of QPS Taser data; data collected by the Taser device that records when it is activated, how many times it is deployed, and for what length of time. The literature review and audit highlighted issues and risks associated with Taser use by the QPS. The review team then conducted an assessment of the QPS Taser policy, procedures and training in light of those findings. The review was published in 2009 (QPS-CMC, 2009) and made 27 recommendations. The report also stated "the paramount importance of ongoing collaboration between the CMC and QPS in monitoring both the implementation of the report's recommendations and emerging research on the effective and safe use of CEWs" (QPS-CMC, 2009, p1). The review (QPS-CMC, 2009) was followed by an evaluation by the CMC, published in 2011 (CMC, 2011). The evaluation by the CMC reported that the QPS had 
...demonstrated a firm commitment to implementing the 27 recommendations from the 2009 QPS -CMC review, investing considerable time and resources to do so. To date, 24 recommendations have been implemented, including all recommendations related to Taser policy and training. Progress continues on the three recommendations related to Taser monitoring and continuous improvement processes that are outstanding.

(CMC, 2011, p.xvii)

The CMC reported positive effects of the changes, including decreased Taser uses. This included a decrease in presentations and deployments, as well as 'drive stun' uses (where the Taser is held against the body rather than the probes being deployed). The CMC also noted decreases in Taser use in certain circumstances, particularly against handcuffed people, and a decrease in multiple and prolonged uses. The CMC concluded that there was "no evidence of widespread misuse" and "no indication of mission creep in terms of officers using Tasers in less serious situations" (CMC, 2011, p. xvii). However, some concerns were raised and suggestions made for continuous improvement in the area of Taser use, particularly regarding Taser use against members of vulnerable groups and ensuring that QPS standards are consistent with suggested best practice internationally. An additional 21 recommendations were presented in the evaluation report that will require further monitoring and evaluation.

The Queensland case study illustrates a slightly different implementation of the SARA model from the Portland case study in that the final stage of assessing the implementation and impact of the recommendations was independently undertaken by the oversight body rather than in collaboration with the police agency. The independence of the evaluation by the oversight agency, rather than jointly with the QPS, may add weight to its report in terms of reassuring public confidence in the system. The case study also illustrates the circularity of 
the SARA model, where the assessment stage can highlight further, or outstanding, concerns that may need additional monitoring or response and further subsequent evaluation.

\section{Conclusion}

The value of a problem-oriented approach to police reform has been described through a variety of examples and case studies, with particular use of the SARA problem solving model. It is important to note that SARA is not offered as a prescriptive model for all oversight work, but as a framework for describing a complementary suite of activity that can contribute to reform. While cases of misconduct continue to arise, and citizens continue to make complaints against the police, there is still a place for reactive oversight. Clearly both deterrence and reform are important functions for external oversight agencies in their endeavour to increase public confidence, reduce police misconduct and improve or enhance police services. Further, in order to fully embrace the Problem Oriented Policing philosophy, responses would need to be innovative, implementation and evaluation would be rigorous, scientific and experimental (or quasi-experimental) (see Tilley, 2010), and efforts would engage a variety of stakeholders. While there is clearly activity emerging in each of these areas, including collaborative efforts between police and oversight agencies, there is a great deal of scope for increasing these efforts, particularly in relation to conducting and publicising evaluations. Oversight agencies have much to offer, if provided with appropriate resources. The case studies presented here show that appropriate partnerships with police are possible and that they can add value to enable problem-oriented work to be undertaken that impacts positively on police service members and communities.

\section{Author Biography}


Dr Louise porter is a Research Fellow in the Centre of Excellence in Policing and Security at Griffith University, specialising in police integrity.

\section{References}

Bertoia, T. (2008). Developing an Early Intervention System for Police Misconduct in a Law Enforcement Agency. Research and Issues Papers, 1. Sydney: Police Integrity Commission.

Chan, J.B.L. (1999). Governing police practice: limits of the new accountability. British Journal of Sociology, 50(2), 251-70.

CMC (2010). The ethical perceptions and attitudes of Queensland Police Service recruits and first year constables 1995-2008. Brisbane: Crime and Misconduct Commission.

CMC (2011). Evaluating Taser reforms: A review of Queensland Police Service policy and practice. Brisbane: Crime and Misconduct Commission.

CPC (2009) 2008-2009 Departmental Performance Report. Surrey, B.C.: Commission for Public Complaints Against the RCMP.

CPC (2010) 2009-2010 Departmental Performance Report. Surrey, B.C.: Commission for Public Complaints Against the RCMP.

CPC (2011) 2010-2011 Departmental Performance Report. Surrey, B.C.: Commission for Public Complaints Against the RCMP.

Docking, M., Bucke, T. Grace, K. \& Dady, H. (2007). Police Road Traffic Incidents: A Study of Cases Involving Serious and Fatal Injuries. IPCC Research and Statistics Series: Paper 7. London: Independent Police Complaints Commission.

Eck, J.E. and Spelman, W. (1987). Problem-Solving: Problem-Oriented Policing in Newport News. Washington, D.C.: National Institute of Justice. Available at https://www.ncjrs.gov/pdffiles1/Digitization/111964NCJRS.pdf 
Ekblom, P. (2005). The 5Is framework: Sharing good practice in crime prevention. In E. Marks, A. Meyer, and R. Linssen (eds.), Quality in Crime Prevention. Hanover: Landespräventionsrat Niedersachsen.

Fitzgerald, G. (1989). Report on the Commission of Inquiry into Possible Illegal Activities and Associated Police Misconduct. Brisbane: Queensland Government Printer.

Force Task Force (2007). Use of force by the Portland Police Bureau: Analysis and recommendations. Portland: Force Task Force to Chief of Police Rosie Sizer.

Force Task Force (2009). Use of force by the Portland Police Bureau follow up: Progress report and analysis of recent data. Portland: Force Task Force to Chief of Police Rosie Sizer.

Goldstein, H. (2003). On further developing problem-oriented policing: the most critical need, the major impediments, and a proposal. Crime Prevention Studies, 15: 13-47.

Gorta, A. (2011). Project Manta Report 2: Managing Command Misconduct Risks. Sydney: Police Integrity Commission.

Grabosky, P. \& Braithwaite, J. (1986). Of Manners Gentle: Enforcement Strategies of Australian Business Regulation Agencies. Melbourne: Oxford University Press. IPCC (2010). Statutory Guidance to the Police Service and Police Authorities on the Handling of Complaints. The Stationery Office, London.

IPCC (2011). Deaths in or following police custody: An examination of the cases 1998/99 2008/09. London: Independent Police Complaints Commission.

Kelman, H. C. (1958). Compliance, identification, and internalization. Journal of Conflict Resolution, 2(1): 51-60.

Knapp, W. (1972) Report of the Commission to Investigate Alleged Police Corruption. New York: George Braziller. 
Livingston, D. (2004). The unfulfilled promise of citizen review. Ohio State Journal of Criminal Law, 1(2), 653-669. 27

Mollen, M. (1994). Commission to Investigate Allegations of Police Corruption and the AntiCorruption Procedures of the Police Department: Commission Report. City of New York, New York.

OPI (2009). Review of the Use of Force by and Against Victoria Police. Melbourne: Office of Police Integrity.

OPI (2012). Ethical Health Assessment Tool: A tool for assessing ethical health frameworks in police services. Melbourne: Office of Police Integrity.

PCCS (2008). Review of Miscellaneous Files by Lothian and Borders Police. Glasgow: Police Complaints Commissioner for Scotland.

PCCS (2009). Report on a User-focused Assessment of the Accessibility of Police Complaints Handling in relation to: Scottish Police Bodies. Glasgow: Police Complaints Commissioner for Scotland.

PIC (2009). Project Odin: Identifying and Managing High Risk Officers in the NSW Police Force. Sydney: Police Integrity Commission.

Porter, L., \& Prenzler, T. (2012a). Police Integrity management in Australia: Global lessons for combating police misconduct. Boca Raton: CRC Press - Taylor \& Francis.

Porter, L.E. \& Prenzler, T. (2012b). Police oversight in the United Kingdom: The balance of independence and collaboration. International Journal of Law, Crime and Justice, $40(3), 152-171$.

Prenzler, T. (2000). Civilian Oversight of Police: A Test of Capture Theory. British Journal of Criminology, 40(4), 659-674.

Prenzler, T., \& Ronken, C. (2001). Models of police oversight: A critique. Policing and Society, 11(2), 151-180. 
Prenzler, T., Ronken, C. (2001). Models of police oversight: a critique. Policing and Society, 11(2), 151-180.

QPS-CMC (2009). Review of Taser Policy, Training, and Monitoring and Review Practices. Brisbane, Australia: Queensland Police Service and Crime and Misconduct Commission. Available at http://www.cmc.qld.gov.au/data/portal/00000005/content/16225001252029372054.pdf

Read, T. \& Tilley, N. (2000). Not Rocket Science: Problem-Solving and Crime Reduction. Crime Reduction Research Series 6. London: Home Office.

Scarman L (1981) Report on the Brixton Disorders of 10-12 April 1981, Cmnd 8427. London: HMSO.

Smith, G. (2009). Citizen oversight of independent police services: Bifurcated accountability, regulation creep, and lesson learning. Regulation \& Governance, 3(4), 421-441.

Tilley, N. (2010). Whither problem-oriented policing. Criminology \& Public Policy, 9(1), 183-195.

Tyler, T. R., \& Blader, S. L. (2005). Can businesses effectively regulate employee conduct? The antecedents of rule following in work settings. Academy of Management Journal, 48(6), 1143-1158.

Walker, S. (2001). Police Accountability: The Role of Citizen Oversight. Belmont, CA: Wadsworth.

Wood, J. (1997). Royal Commission into the New South Wales Police Service: Final Report. Sydney: NSW Government Printer. 
Figure Captions

Figure 1: Representation of the SARA model 
Figure 1:

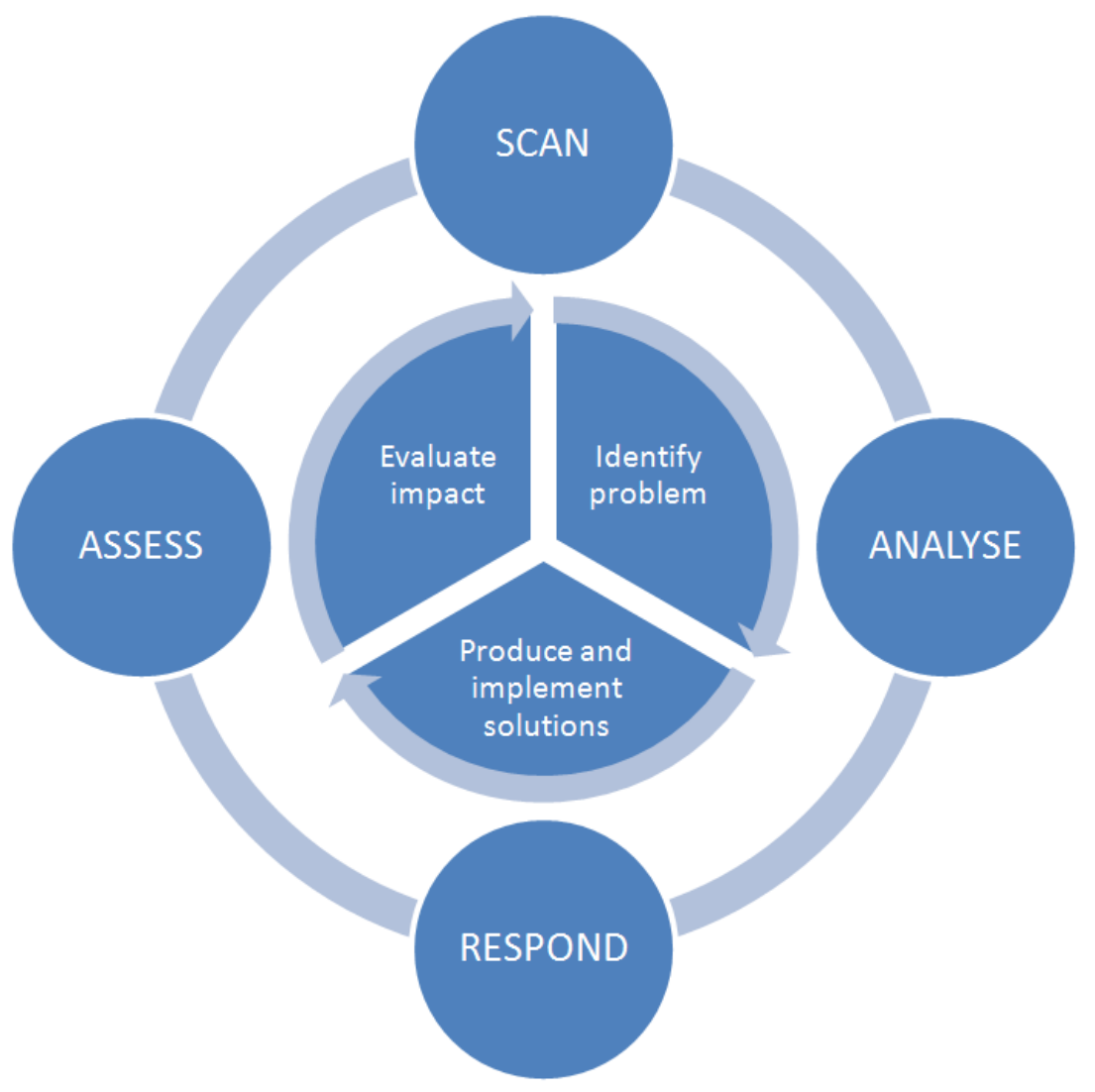

